PROCEEDINGS OF

THE THIRD SCIENTIFIC CONFERENCE

ON ANDEAN ORCHIDS

POSTERS

CONSERVATION SCIENCE

ECOLOGY

SYSTEMATICS 


\title{
APLICACIÓN DE LA TÉCNICA DE ENCAPSULACIÓN - DESHIDRATACIÓN PARA LA CRIOCONSERVACIÓNDE SEMILLAS Y PROTOCORMOS DE ONCIDIUM STENOTIS (ORCHIDACEAE)
}

\author{
Alberto Roura ${ }^{1,3}$, Karina Proaño $^{2} \&$ Mónica JadÁN $^{1}$ \\ ${ }^{1}$ Escuela Politécnica del Ejército, Departamento de Ciencias de al Vida \\ Carrera en Ingeniería en Biotecnología, Laboratorio de Cultivo de Tejidos, Sangolquí-Pichincha \\ Av. Del Progreso S/N, Ecuador \\ ${ }^{2}$ Escuela Politécnica del Ejército, Departamento de Ciencias de al Vida \\ Carrera en Ingeniería en Biotecnología, Laboratório de Biología Molecular Vegetal, Sangolquí- \\ Pichincha, Av. Del Progreso S/N, Ecuador \\ ${ }_{3}^{3}$ Autor para correspondencia: ajroura@gmail.com
}

El presente trabajo pretende desarrollar un sistema que posibilite la crioconservación de semillas y protocormos de Oncidium stenotis en nitrógeno líquido $\left(-196{ }^{\circ} \mathrm{C}\right)$, con el uso de la técnica de Encapsulación-Deshidratación. La primera fase del proyecto consistió en tomar dos fracciones de las semillas, una de ellas fue puesta a germinar en medio Knudson liquido adicionado: ácido $\alpha$-naftalén acético y ácido giberélico y la segunda fracción en medio Knudson sólido ( 7 gL-1 de agar) enriquecidos con: benziladenina, ácido indolacético, ácido $\alpha$-naftalén acético y ácido giberélico. Ambas fracciones se incubaron a $23 \pm 2{ }^{\circ} \mathrm{C}$ y con un fotoperíodo de 12 horas luz. La adición de diferentes concentraciones de reguladores de crecimiento en ambas fracciones se la realizó con el fin de acelerar el proceso de germinación. La fase que se realizará posteriormente es encapsular las semillas y protocormos en alginato de sodio al 3\%, las cápsulas posteriormente serán deshidratadas en concentraciones crecientes de sacarosa $0.15 \mathrm{M}(24 \mathrm{~h}), 0.25 \mathrm{M}(24 \mathrm{~h})$ y $0.5 \mathrm{M}$ (24 h) para luego ser colocadas en sílica gel por 5 horas. La crioconservación se efectuará por inmersión directa en nitrógeno líquido durante una hora. El descongelamiento se realizará a baño maría $\left(37^{\circ} \mathrm{C}\right)$ por un minuto, luego las cápsulas que contengan semillas se sembrarán directamente y los protocormos se recultivarán sin las cápsulas en medio Knudson sólido, con la adición de diferentes concentraciones de Benziladenina e Ácido Indolbutírico, para buscar el medio adecuado de resuperación postcongelamiento. 